\title{
Towards E-Learning in Higher Education in Libya
}

\author{
Amal Rhema and Iwona Miliszewska \\ Victoria University, Melbourne, Victoria
}

\author{
Amal.Rhema@live.vu.edu.au; Iwona.Miliszewska@vu.edu.au
}

\begin{abstract}
The growing influence of technologies on all aspects of life, including the education sector, requires developing countries to follow the example of the developed countries and adopt technology in their education systems. Although relatively late, the Libyan government has eventually responded to this challenge and started investing heavily in the reconstruction of its education system, and initiating national programs to introduce information and communication technology (ICT) into education. In addition, there are plans to establish virtual campuses in many universities and colleges to provide an advanced platform for learners and instructors. This paper presents the higher education context in Libya and outlines the applications of ICT and e-learning in Libyan higher education to date. It discusses the issues that need be considered and addressed in adopting ICT in the learning and teaching processes including technological infrastructure, curriculum development, cultural and language aspects, and management support. The paper also outlines the prospects for the integration of e-learning into Libyan higher education and concludes with proposing an integrated approach to advancing the introduction of e-learning in Libya.
\end{abstract}

Keywords: developing country, e-learning, ICT teacher training, information and communication technology, Libyan higher education, technology transfer, technological infrastructure.

\section{Introduction}

Libya has the highest literacy rate in the Arab world, and the United Nation's Human Development Index, which ranks standard of living, social security, health care and other factors for development, keeps Libya at the top of all African countries. Libya has always been enthusiastic to ensure access to appropriate education for all members of the society, males and females. Government reform plans to improve and develop ICT infrastructure in Libya and it seeks to develop and renovate the entire educational process, including the development of curricula and updating its scientific content; adopting ICT in education including higher education is an essential factor in its overall development plans. Libya wants to play a leading role on the African continent by promoting and sponsoring major initiatives and projects, including those in the neighboring countries of Chad, Niger, and Rwanda. However, the challenges of poor and undeveloped existing

Material published as part of this publication, either on-line or in print, is copyrighted by the Informing Science Institute. Permission to make digital or paper copy of part or all of these works for personal or classroom use is granted without fee provided that the copies are not made or distributed for profit or commercial advantage AND that copies 1) bear this notice in full and 2) give the full citation on the first page. It is permissible to abstract these works so long as credit is given. To copy in all other cases or to republish or to post on a server or to redistribute to lists requires specific permission and payment of a fee. Contact 0HPublisher@InformingScience.org to request redistribution permission. infrastructure and a lack of skilled, qualified and ICT-savvy teachers present a great challenge to the current reform process (Hamdy, 2007).

Over the last twenty years, developed countries and emerging economies have introduced ICT to enhance all their sectors of society including the educational sector. This change has had a significant impact on the curricula, the methodol- 
ogy of teaching, and learning processes. Gerry (2005) sums up the history of ICTs in education by explaining that the period from 1981 to the current age has seen the educational use of computers developing from standalone data processors in computer labs, through to accessing the Web, to being able to provide integrated Web services for teaching and learning, resource collections, student records, administration, professional development and community relations now.

E-Learning is an ideal learning environment using modern means of information technology, through the effective integration of information technology and the curriculum to achieve, a new learning style which can fully reflect the main role of the students to thoroughly reform the traditional teaching structure and the essence of education, to train large numbers of high quality personnel. (Ma, Wang, \& Liang, 2008, p. 54)

E-learning has started to emerge in many developing countries where it is likely to have a huge potential for governments in helping to meet an increasing demand for education and address the growing decline of trained teachers (UNESCO, 2006). Higher education institutions throughout the world are in a period of rapid change, as "Changes occurring in the primary processes of higher education courses and degree granting are closely related to the contextual trends of virtualization, internationalization, lifelong learning and customer orientation that are part of society in general" (Collis \& Moonen, 2001, p. 30). In this context, traditional universities have no choice but to significantly alter their instructional methods to keep pace with developments spurred by the Internet. Thus, adopting and adapting to "the technology of the 21 st century" is unavoidable for everyone in society and in particular in the educational context (Ali, 2003; Collis \& Moonen, 2005).

This paper presents the higher education context in Libya, outlines the applications of ICT and elearning in Libyan higher education to date, and discusses the challenges of, and prospects for, further integration of e-learning in higher education in Libya.

\section{Higher Education Context in Libya}

In Libya, higher education is offered in universities, both general and specialized, and higher vocational institutes. These include teacher training higher vocational institutes; higher institutes to train trainers and instructors; polytechnic institutes, and higher education institutes for technical, industrial and agricultural sciences. Several higher education institutes for teacher training were founded in 1997. New scientific institutions called Scientific Research Centres have been created in such fields as Health and Pharmacy, Education, the Environment, and Basic Sciences; they are both educational and research institutions. The National Authority for Scientific Research is responsible for higher education and research and the University People's Committee, chaired by a Secretary, manages university education. Each Faculty within a university also has a People's Committee, chaired by the Dean and with heads of departments as members. Each university manages its administration and its budget. University-level education includes three major sections: university education (lasting four to seven years), university vocational and technical education (lasting three to five years), and advanced graduate studies. Education in Libya is free to everyone from elementary school right up to university and post-graduate study abroad. Postgraduate studies at home (in Libya) are fee-paying but also subsidized by the government; for example, the cost of a Masters' degree at the Academy of Postgraduate Studies may cost around 3,000 Libyan dinars, or about USD \$2,300. In addition, schools and universities are located throughout the country to facilitate better access to educational opportunities and, in an effort to meet the needs of students from remote and hard-to-reach areas, mobile classrooms were introduced in 2006 to cover all parts of Libya (Hamdy, 2007). 


\section{History of Higher Education}

After Libya's independence in 1951, its first university, the Libyan University, was established in Benghazi. It was named the Faculty of Arts and Education and was followed in 1957 by the establishment of the Faculty of Science in Tripoli. In 1957, the Faculty of Economics and Commerce was founded, followed by the Faculty of Law in 1962, and the Faculty of Agriculture in 1966; by 1967, the Libyan University witnessed further expansion with the inclusion of both the Faculty of Higher Technical Studies and the Higher Teachers Training College. The Faculty of Medicine was founded in 1970 and, in the same year, the Islamic University in Al-Bayda was incorporated by the Libyan University under the name of the Faculty of Arabic Language and Islamic Studies. In 1972, the Faculty of Oil and Mining Engineering was founded and then moved in the late 1970s to the Brega Oil Terminal Complex.

In 1973, the Libyan University was separated into two independent universities: the University of Tripoli and the University of Benghazi; these universities were later renamed to the University of El-Fateh in Tripoli and the University of Garyunis in Benghazi respectively (Libya - Education, 2009). Because of the increasing number of students who have enrolled in higher education since 1981, the university system was restructured and many public universities were launched (ElHawat, 2003); currently, there are 18 public universities consisting altogether of 148 specialized faculties and more than 500 specialized scientific departments.

University level studies are divided into three stages Bachelor's degree, Master's degree, and Doctorate:

1. First stage: Bachelor's Degree; conferred after four to five years' university study (five years in Architecture and Engineering) in universities and higher institutes.

2. Second stage: Master's Degree; conferred after two years' study following a Bachelor's Degree and offered mostly by large universities, such as Garyounis and El-Fateh.

3. Third stage: Doctorate; may be awarded after a further two years of research in such fields as Arabic, Islamic studies and Humanities and is conditional upon the submission of a thesis. Many students are still sent abroad to pursue doctoral degrees (Clark, 2004).

In addition, higher education institutes provide higher vocational and technical education of three to five years' duration in such fields as Electricity, Mechanical Engineering, Finance, Computer Studies, Industrial Technology, Social Work, Medical Technology and Civil Aviation. The qualification awarded after three years is the Higher Technician Diploma; otherwise, after four or five years, a Bachelor's degree is awarded. Upon completion of their studies, graduate technicians are assigned to work on development projects.

In the late 1990s, Libyan authorities have invited the private sector to play a role in the nation's education system. Since then, more than 1,000 privately funded primary and secondary schools and institutions have been established. In addition, the private sector has created more than 30 private universities that provide education in all disciplines.

\section{Government-funded Universities}

Libya's population of approximately 6.2 million includes around 2.7 million students; the number of university students has increased to more than 300,000, with an extra 90,000 enrolled in the higher technical and vocational sector. Since 1975 the number of universities has grown from two to nine and after their introduction in 1980, the number of higher technical and vocational institutes currently stands at 84; Figure 1 illustrates the locations of higher education institutions in Libya. The overall responsibility for all aspects of education in Libya lies with the Libyan Ministry for Education. The Ministry shares the responsibility with local education committees that 
control the education programs within their geographical area; the Ministry controls all the committees in the country and its Higher Education Department oversees the operations of all universities in Libya.
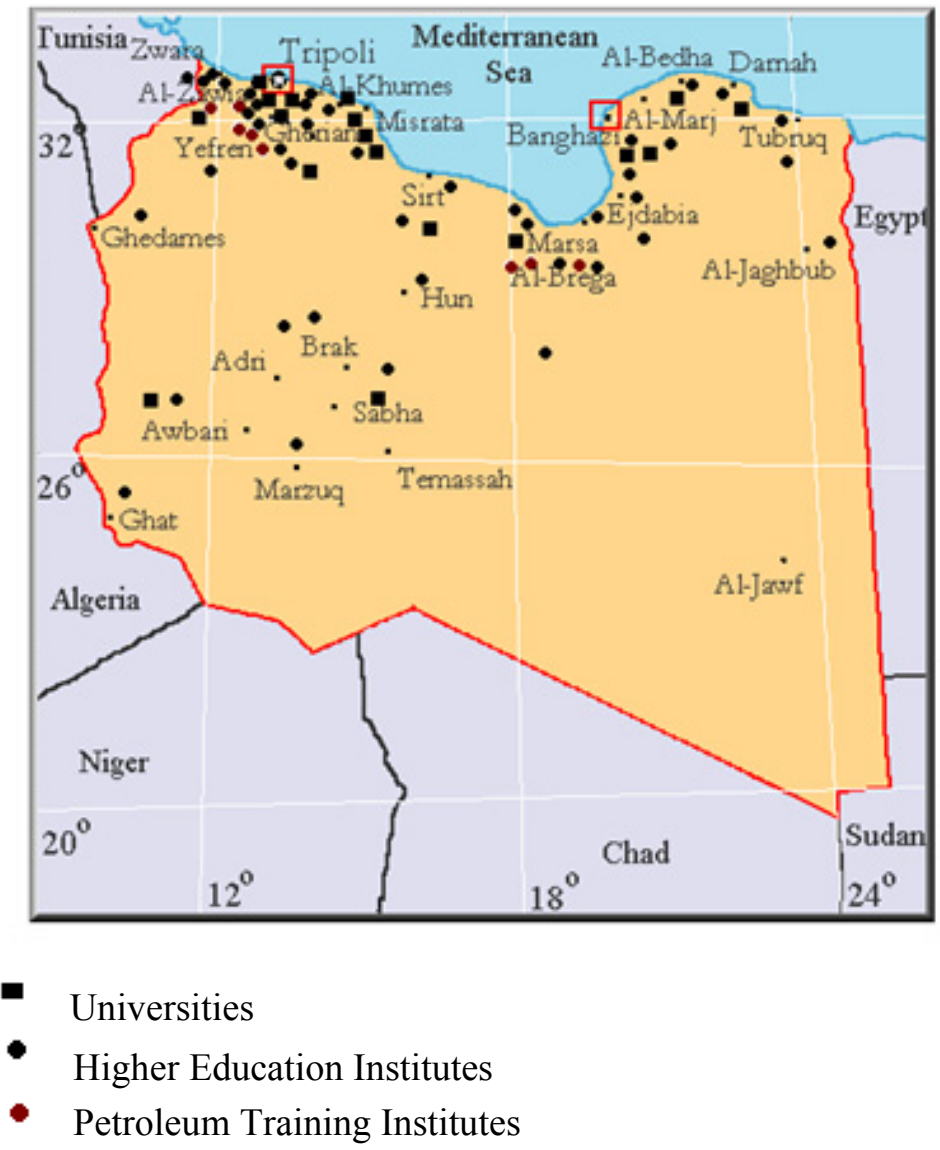

Figure 1: Higher education institutions in Libya

Currently, there are 18 government universities in Libya; Al Fateh University and Garyounis University are the oldest and the largest, with student populations of 115,000 and 60,000 respectively. In addition to universities, there are 264 government-funded higher education institutes that provide education in the areas of administration and management, technology, creative art, and teacher development. Finally, another eight institutes - petroleum training and qualifying institutes - are dedicated to the training and education of personnel for the oil industry. Five of these institutions are located in the capital and main cities, and three of them operate in regional areas.

\section{Teacher Education}

There are several types of teacher education in Libya including courses for pre-primary and primary/basic school teachers, secondary school teachers, and higher education teachers. Primary school teachers are trained in three to four years in State Higher Teacher Training Institutes at intermediate school level; a number of centres for in-service training were opened in 1995-96. A training centre was also opened to train teachers for technical and vocational basic and intermediate levels. Secondary school teachers are trained in four years at higher education level (Faculty 
of Education). Teachers at intermediate training centres are graduates of the higher technical institutes.

MA holders can become assistant lecturers. They can be promoted to lecturer status after three years of teaching. They are promoted to assistant professor status after having taught for four years and submitted three theses evaluated by a scientific committee of three teaching staff members. PhD holders are appointed as lecturers and promoted to assistant professor status after four years of teaching. They are then promoted to joint professor status after four further years of teaching and submission of published scientific theses evaluated by a scientific committee of three teaching staff members. Teachers are promoted to the status of Professor after being a joint Professor and having taught for five years and presented three published theses evaluated as above (Clark, 2004).

\section{Non-traditional Studies}

The Libyan educational system offers possibilities for non-traditional studies. These include distance higher education and other forms of non-formal higher education. Distance education is provided by the Open University, created in 1990. Its main centre is in Tripoli but it has opened 16 other centres around the country in Benghazi, Sebha, Ejdabia, Derna, Misurata and El-Kufra. The number of credits needed for graduation is between 120 and 150 credit hours as per the school year system. Curricula and teaching programs are conveyed via written and audiovisual material (learning packages).

Non-formal studies consist of short postsecondary courses for training paramedical personnel, and inspectors of hygiene (Hamdy, 2007).

\section{E-Learning in Libyan Higher Education}

Like in most developing countries, the use of ICTs and the implementation of e-learning in Libya are still in an early stage. While some Libyan universities, such as Alfateh University, Garyounis University, and Academy of Postgraduate Studies and Economic Research, have the basic ICT infrastructure (such as computers, Internet access, and a local area network), they still use the "traditional" model of education; this model is based on face-to-face interactions in, and outside of, classroom between students and teachers, and learning activities that are only available on campus. Libyan Open Universities (LOPs) offer students the opportunity to study at home; however, the learning experiences are traditional too, as the universities rely largely on printed learning materials. This is beginning to change, as recently several institutions have introduced electronic resource repositories, e-libraries. These universities provide an opportunity to acquire higher education to students with work and family commitments, and to students from the regional areas of the country. LOP students study at home and come to the university only at the end of semester to sit exams.

In 2005 a national policy for ICT in education was established in 2005; the policy is managed by the Ministry of Education and the Ministry of Vocational Training with the support of other parties such as the country's major telecommunication providers the General Postal and Telecommunication Company (GPTC) and Libya Telecom and Technology; the co-operation between the government and the private sector aims to improve Libya's ability to implement large-scale ICT initiatives. In a drive towards modernity, this policy aims to enable ICT access, provide ICT infrastructure and tools, and help develop ICT skills on a large scale in all sectors of the community. However, its main purpose is to use ICT and e-learning as instrumentalities of modernity to improve and enhance the quality of Libyan education through: 
- Adopting modern, technology-assisted educational techniques and methods;

- Supporting the scientific community to get involved in research within the general Libyan population;

- Encouraging the private sector to engage in funding higher and specialist education;

- Developing open and distance learning; and,

- Boosting the profile of higher education.

\section{Current ICT Initiatives and Projects}

Several ICT initiatives are currently in progress in Libya. One major project, sponsored by UNESCO and the Libyan government, involves the establishment of the Libyan Higher Education and Research Network (LHERN); to this end, Local Area Networks (LANs) will be built within all 149 faculties from various university campuses and institutes and, in addition, a Wide Area Network (WAN) will join the various higher education institutions. The project foresees the creation of a national ICT resource centre for educators and the automation of university management systems through ICT, such as student information systems, university procedures, and financial operations (UNESCO, 2005b). Thus, the project will involve the creation of digital libraries and portals of educational resources, and the development of ICT enhanced learning solutions such as e-learning, tele-education, and telemedicine. In addition, the project will provide training to faculty in digital literacy, basic ICT skills, and using ICTs in teaching and courseware development; and, staff will receive training in system administration, and operation of media centres.

In another major development, the Department of Computers and Networks oversees the implementation of the National Computer project, which aims to supply and install more than 150,000 computers in nearly 5,000 computer laboratories at educational institutions, including higher education institutions. The Department also supervises the implementation of a national project to link all educational institutions with an advanced telecommunications network using telephone lines, satellite, and wireless communications (The General People's Committee of Education, 2008). This project will particularly assist in expanding and improving Libya's current eexamination system. This computerized system is used to manage the results of final examinations of secondary school students and, based on the results, determine their subsequent university destination.

\section{Implementation of ICT in Education}

Libyan national ICT policy for education aims to provide access to ICT tools and build a strong infrastructure. It also encourages research and development to ensure the provision of proper learning materials, tools, methods and media and to build a strong society capable of competing in the global arena. One of the main objectives of the national ICT policy for education is human resource development, and the investment in human resources is the key factor to achieve the goals and objectives of the national ICT strategy. UNDP and UNESCO work hand in hand with Libyan government agencies to ensure appropriate and timely implementation of the ICT strategy. This support also opens the door for the partner community and encourages investment in Libya. However, Libya has faced a number of constraints and challenges especially during the embargo (which ended in 2006). Therefore, the implementation of the ICT policy is still at an early stage, as is access to ICT tools. The implementation of the national ICT policy and the development projects in different domains still lag behind. In addition, there is an acute shortage of ICT qualified and trained teachers, who are needed to bring ICT into classrooms and educate a new generation of technically qualified students (Hamdy, 2007). 
The drive towards the deployment of e-learning in Libya is motivated by the country's desire to further develop and improve its education system, especially higher education. Therefore, Libya now is working hard to provide all universities with technological infrastructure as soon as possible. There have also been developments in the use of the new technologies in education. For example, in 2008 Libya introduced an electronic system for submitting specialized secondary education examinations; the project proved to be a success and the General People's Committee of Education aims to expand it to other educational areas. Further pilot initiatives to implement elearning have also started, initially in primary schools. Recently, a Libyan educational technology solutions provider, MCIT, together with its partner, the Ireland-based Riverdeep, has developed a successful e-Learning pilot project covering six schools in Tripoli where MCIT designed and provided the entire IT, network and power infrastructure for the schools and supported the systems and applications under the standards developed by Riverdeep (The General People's Committee of Education, 2008).

\section{Challenges for E-learning}

Libyan higher institutions still face many challenges in terms of the implementation of ICT and elearning in teaching and learning. These challenges are associated with: the cultural and linguistic background of students and instructors, and their awareness of and attitudes towards e-learning; the underdeveloped technological infrastructure and the often prohibitive cost of educational technologies; the lack of local expertise in curriculum development for e-learning; and, the lack of educational management mechanisms to support e-learning initiatives.

\section{Culture and Language}

Culture is defined "as the collective programming of the mind that distinguishes the members of one group or category of people from another" (Hofstede, 1980, p. 25); therefore, people's perceptions of ICT and e-learning differ, as they depend on their backgrounds. Accordingly, the design of an e-learning system needs to consider cultural differences and sensitivities of its users; this includes consideration for the various dimensions of the e-learning environment (Khan, 2003). For example, in designing interfaces for an e-learning system for learners worldwide, cultural communication and ethical issues must be taken into consideration; "Cultural factors are increasingly cited as significant influences on IT adoption" (Elbeltagi, McBride \& Hardaker, 2005, p. 46). In Libya and in the Western cultures for instance, the "thumbs-up" sign signifies approval, whereas in other cultures such as Bangladesh, it is used to challenge people. Attitudes towards eye-to-eye contact represent yet another example of cultural differences. Eye-to-eye contact is often avoided in Libya and other Arabic cultures because humility is an important aspect of the Islamic religion. However, avoiding eye contact in Western societies might be interpreted as a sign of submission and weakness, and sometimes ignorance. The design should also consider appropriate reading directions for example, importantly for Libya, right-to-left to suit the Arabic language; likewise, text justification and navigation systems should be fixed on the left hand side. In addition, the choice of icons, symbols, objects, and colors needs to be carefully considered; for example, to many users in the Western countries will find an image of a dog on a Web page harmless, or indeed friendly, whereas users in Libya would find a similar Web page quite offensive.

Libyan families are still mostly traditional in their customs, attitudes, behaviors, and interaction and communication patterns and protocols. Thus, the Libyan family has a limited ability to follow the growth and development of technology, embrace it, and then transfer it in the form of attitudes and behaviors onto their children. Also, teachers as well as students are still mostly unaware of the potential of e-learning. 
The language barrier is a significant inhibiting factor in adopting e-learning in developing countries (particularly in Libya). The official language in Libya is Arabic and the level of English skills is low; Arabic is absolutely different from English: the two languages have nothing in common. However, most of the learning resources (including the all-important freeware), software, and Web contents are in English, thus rendering them un-useable to a great majority of Libyans and making it very difficult to integrate ICT and e-learning in the Libyan education system.

\section{Attitude, Awareness, and Motivation}

Awareness goes along with attitude and "positive attitude towards ICTs is widely recognized as a necessary condition for the effective implementation" (Woodrow, 1992, cited in Sife, Lwoga, \& Sanga, 2007, p. 7). Developing countries still lack sufficient awareness of ICTs and e- learning. In Libya, the level of educational technology awareness and even basic computer skills is generally low among educators in all types of higher education institutions, which leads to resistance in adopting ICT for teaching. Most students and teachers have had little, or even no, experience in using a computer; and those who are familiar with computers, generally only use them as a tool for entertainment and communication (the Internet). Thus students tend to feel anxious and even worried when engaging with technology for learning purposes, because of their perceived a sense of incompetence. On the other hand, they find interacting with computers pleasant, helpful and easy, as they use online chat-rooms, and download music and films.

Student motivation is a factor that affects students" satisfaction and capacity: "Highly motivated students perform well in most cases whereas non-motivated students tend to drop out" (Andersson \& Grönlund, 2009, p. 5). Personal motivation is one of the main reasons for success or failure in the integration of ICTs and adopting e- learning in teaching and learning. And conversely, ICT may have an impact on students' motivation. Many researchers indicate that ICT increases student engagement because it provides opportunities to shift from teacher-centered to studentcentered learning which attracts students and leads them to enjoying learning. However, many Libyan students, particularly those who struggle with computers, lack motivation for e-learning, because the lack of exposure makes it difficult for them to appreciate its potential benefits.

\section{Technological Challenges}

Technology is a fundamental factor in the development of e-learning, and it refers to requirements such as networks, hardware, software, computers, radio, audio cassettes, video, and Internet access: "The technological dimension of the e-Learning framework examines issues of technology infrastructure in e-learning environments. This includes infrastructure planning, hardware and software" (Khan, 2003, p. 2). Another factor related to technology is software and interface design: "The interface design refers to the overall look and feel of e-learning programs. Interface design dimension encompasses page and site design, content design, navigation, and usability testing" (Khan, 2003, p. 2). Thus, educational software should be easy to use and a learning management system should support the selected learning models and pedagogies. Lastly, adequate technical support is an important part of the implementation and integration of ICT and e-learning in an education system (Sife et al., 2007).

Libya faces a number of challenges on the technological front. As outlined earlier in this paper, Libya still largely lacks the required technological infrastructure; however, many infrastructure projects are currently in progress. While computer laboratories are available in most Libyan higher institutions, the lack of adequate network facilities places serious restrictions on Internet access. The use of educational software within institutions is limited too, as there are very few products on the market that are available in Arabic, and the country's lacks the capacity to develop its own products. Lastly, the technical support is almost unavailable in Libya (as the case in 
many developing countries), which leads to delays in installation, operation, and maintenance of equipment and software, and further discourages users.

\section{Curriculum Development}

"The curriculum is becoming more dynamic and interactive as a result of the many kinds of ICTbased learning activities, projects and software applications being developed" (UNESCO, 2005a). By using ICTs, it is possible to create several different kinds of courses, each providing learners with a distinctive type of learning experience and each suited to different situations (Horton, 2000). Baylor and Ritchie (2002, 398 cited in Hu \& Webb, 2009, p. 2) concluded that "regardless of the amount of technology and its sophistication, technology will not be used unless faculty members have the skills, knowledge and attitudes necessary to infuse it into the curriculum." Because e-learning is different from traditional learning, the curriculum and pedagogical methods need to be modified and developed to employ ICT application effectively, and they should be specifically designed to fit the e-learning setting (Andersson \& Grönlund, 2009); thus, curricula developers must be able and qualified to redesign courses according to the specific sort of ICT and e-learning. In this respect, Libya faces a double challenge: first, Libyan higher education curricula are standardized that is, it is prescribed and controlled nation-wide by the Ministry for Higher Education. So, there is a need to overcome the constraints and reliance on standardized curriculum. Second, the development of new pedagogical scenarios for e-learning sittings requires willing participation of academics and considerable assistance from educational developers with experience in e-learning; such expertise is not available in Libya yet.

\section{Management Support}

Teachers generally are more motivated and committed when they feel supported and encouraged by the administrators (Andersson \& Grönlund, 2009). According to Mapuva (2009, p. 3), "Institutional leaders are a determinant factor, given their decision-making roles which could either make-or-break the e-learning projects by either facilitating or impeding its implementation within their institutions. "So, administrative support can be regarded as essential to the successful adoption of ICTs into the educational processes. However, administrators in Libyan institutions generally lack the ability to deal with educational problems and tend to struggle with the management of institutional inefficiencies. Therefore, it will take some time and effort for the administrators to come on board of e-learning; they will need to develop an understanding of the technical, financial, pedagogical, and administrative dimensions of ICTs in education.

\section{Prospects for E-learning in Libya}

While the incorporation of e-learning in Libya faces many challenges, as outlined above, the recent developments in the Libyan government's direction towards ICT have opened an opportunity to adopt e-learning for all the levels of education including higher education. The government's approval and support is likely to act as a catalyst for change; only in September of 2009, the government commissioned a USD 60 million pilot e-learning project from the Irish provider Riverdeep. Also, the recent allocation of USD 35 billion by the Organization for the Development of Administrative Centers (ODAC) to improve Libya's infrastructure, diversify its economy and enhance the quality of life for the community (Austrade, 2009) is expected to have a positive impact on e-learning initiatives in the country. The development and adoption of e-learning in Libya is also likely to be helped by: educational technology transfer from, and collaboration with, developed countries; growing awareness of e-learning and expectations of students; successful deployment of e-learning initiatives by similar developing countries; the development of e-learning expertise in Libyan educators; and, an ongoing research to inform the development process. 


\section{Technology Transfer}

Recently, many traditional education systems have shifted towards new methods of teaching and learning thanks to the proliferation of ICTs. The continuous advances in technology have led to a greater distribution of knowledge transfer. This change is particularly significant for developing countries which lack the infrastructure, resources and attitude to implement advanced educational practices on their own (Iahad, Dafoulas, Milankovic-Atkinson, \& Murphy, 2004). Bozeman (2000, p. 629) defines "technology transfer" as "the movement of know-how, technical knowledge, or technology from one organizational setting to another". In the educational context, technology transfer includes the exchange of knowledge, techniques and methods of teaching and learning between educational institutions nationally and internationally. Technology transfer to developing countries requires particularly careful consideration (Straub, Loch \& Hill, 2001); as Klauss stated:

It is evident that both the selection of a technology and the strategy of transfer to developing countries have to be very carefully considered to ensure that an appropriate technology is chosen, that it is effectively adopted/ adapted and institutionalized, and that it is sustainable over time. (Klauss, 2000, p. 277)

A large number of initiatives are currently in progress in developing countries to reuse existing technologies, which have been transferred from developed countries, to adopt e-learning and integrate ICT in their educational systems. Technology transfer has enabled many developing countries to adopt e-leaning applications, for example Web-based Learning such as WebCT and Moodle is widely used in Egypt, whereas the Blackboard course-management system is being used in six schools in Tripoli in Libya. Technology transfer brings many educational changes to Libya and other developing countries in terms of Internet infrastructure and services, curriculum development, teaching and learning resources, administration, and training for the technicians and ICT experts at institutions. Currently, Libyan curriculum is being developed and reviewed, taking into consideration the global changes and ICT revolution, using the assistance of UNESCO and some developed countries.

\section{Changing Student Expectations}

E-learning has the potential to meet the Libyan students' needs and expectations by addressing their educational problems. According to previous research, which reported on an attempt to introduce web-based learning in the Data Analysis Department of the Faculty of Economics and Accounting of the Aljabal algharbi University in Gharian in Libya (Rhema, 2005), e-learning seems to have provided responses to several problems identified by the students; it afforded alternative ways of communicating with teachers and fellow students, provided a greater variety of learning resources and modalities, extended the flexibility and quality of group-work, and improved the opportunities for providing students with feedback on assessment tasks. Some of the students' responses reported in Rhema's study included the following statements:

"It appeared that the traditional classroom setting is not sufficient to assure effective and efficient communication between instructors and us and that other means of communication and education have to be found."

"We do not have a wider choice of resources and modalities of study materials."

"The possibilities to collaborate in group work assignments are too limited to work at fixed times in the day; we could not work when we are in different places. When ones misses the class session he/she will face difficulties to understand the lesson because the only key learning materials are the instructor notes on the class." 
"The instructors stopped giving individual and group assignments to us because they could not find the time to give face-to-face feedback. The only way of course assessment is two exams per semester. Furthermore, there are no collaborations between students to interchange knowledge between each other."

So, it is clear that Libyan students appreciate the difficulties of the Libyan education system and are opening up to alternatives that could offer improvements. The task is to convince them that elearning is a viable alternative; well trained teachers with positive outlook on ICT are likely to play a vital role in this task. However, special training is necessary to raise their awareness of ICT and its uses; the importance of training and development have been highlighted by Schuler and Jackson (as cited in Mapuva, 2009, p. 6) who view these as initiative tools that can be employed to enhance the knowledge and skills necessary for work-related performance. his training will play a dual role: it will change the attitude of educators towards ICT and e-learning and, in turn, increase students' interest and motivation for ICT.

\section{Successful Initiatives in Neighboring Countries}

There is a need to document and share the best practices in the field of e-learning with other countries both those which are interested in introducing it and those which have successfully implemented it in their education systems. Development partners, particularly organizations and companies working in the area of promoting e-learning, can facilitate this process of documentation and organize events to share and exchange the best practices and experiences.

Many organizations in Libyan neighboring countries such as Egypt and Tunisia have implemented and continue to expand various e-learning initiatives. Egypt is a particular interesting case, in that its technological infrastructure is similar to that of Libya (relative to population), as illustrated in Table 1; yet Egypt has a much greater number of Internet users compared to Libya.

Table 1: ICT usage in Libya \& Egypt (The World Factbook, 2009)

\begin{tabular}{|l|c|c|}
\hline \multicolumn{1}{|c|}{ Indicator } & $\begin{array}{c}\text { Libya } \\
\text { (pop. 6.5 M) }\end{array}$ & $\begin{array}{c}\text { Egypt } \\
\text { (pop. 74 M) }\end{array}$ \\
\hline Telephones - main lines in use (2008) & $1,033,000$ & $12,011,000$ \\
\hline Telephones - mobile cellular (2008) & $4,828,000$ & $41,272,000$ \\
\hline Internet users (2008) & 323,000 & $11,414,000$ \\
\hline Internet hosts (2009) & 11,751 & 177,443 \\
\hline
\end{tabular}

In Egypt, the Faculty of Engineering at the University of Cairo is setting an example with elearning related activities such as conversion of text books to interactive CD-ROMs and pilot projects in virtual classrooms. Also, the American University in Cairo is using WebCT as a learning management system and offering a centre for helping the university teachers to convert their materials to web-friendly format. Furthermore, numerous e-learning projects have been launched by a number of Egyptian government universities since 2002, these projects include initiatives at the Cairo University, National projects such as HEEPFE, Higher Education Enhancement Project founded by the World Bank, UNESCO endorsed open source platform for higher education, MEDA and Tempus projects supported by European Commission Directorate General for Education and Culture (Abdel-wahab, 2008).

In Tunisia, the e-learning team of the Higher School of Sciences and Techniques of Tunis (ESSTT) has worked for several years on designing the first Tunisian e-learning platform called 
Waheeb; this Web-based learning platform provides a fully integrated student environment, learning management system, and a range of custom content creation and publication tools. Importantly for Libya, Waheeb can be used completely in Arabic language; of course, it also supports other languages such as English and French (Chorfi \& Jemini, 2002).

\section{E-education Capacity Building}

While instructors play a vital role in the educational process, most of the instructors in Libya are not familiar with e-learning and in need of training. The government has acknowledged the need and provided continuing intensive training courses for instructors through the General Center for Teacher Training. The training courses have been designed to raise the efficiency of instructors, supervisors, and administrators in educational institutions; produce educators who are capable to use modern teaching techniques and who have sufficient computing skills; and, raise the awareness of e-learning issues and prospects. The Centre provides many workshops for educators to explore the role of e-learning in responding to the teaching and learning needs, and to focus more on how to build a consolidated approach to e-learning for capacity development. According to the 2008 report of The General People's Committee of Education, "the Center has trained thousands of teachers and inspectors, social workers, laboratory technicians, and schools principles, and also plans to re-skill and up-skill more than 15,000 thousand teachers in various scientific and educational fields at different levels".

Another centre, the Libyan Dutch Training Centre (LDTC), is being developed in Tripoli; the final phase of the development will be completed in 2010 and the centre will provide services to upgrade the qualifications of teachers and graduates in the field of technology. The training programs are considered a vital starting point in the development of e-learning in Libya. While they have a positive general impact on the development of the Libyan education sector, they specifically encourage the use of e-learning and the adoption of its tools and technologies to facilitate wider access to learning and improvement of educational achievements in Libya.

The Libyan government also offers opportunities for students to complete their higher and further education studies overseas; currently, more than 5,000 Libyan students supported by full government scholarships are studying abroad in the UK, Ireland, Germany, Canada, the USA, Malaysia, Indonesia and Australia. In addition, the government provides further educational support to nearly 1,000 students who have excelled in their studies in targeted disciplines of national importance; these high-achieving students are provided with full scholarships to pursue undergraduate and postgraduate studies and lead the development of model educational establishments for the future Libyan generations.

\section{New Research for Further Development}

A PhD research study is now being undertaken at Victoria University, in Australia as a further attempt to better understand the current situation in Libyan higher education institutions in terms of e-learning and inform future developments. The study aims to investigate and document the challenges, enablers, and characteristics of educational settings as related to e-learning in selected higher education institutions in Libya. Following the investigation and review of the learning contexts, the study will present a comparative analysis of the current traditional learning environments of higher education in Libya and future non-traditional alternatives that incorporate elearning. The research will provide recommendations that might assist higher education decision makers and instructors in the state of Libya in developing successful initiatives and reforms related to e-learning. 


\section{Conclusion}

This paper reflected on the higher education context in Libya and the applications of ICT and elearning in Libyan higher education to date; it also discussed the challenges for and prospects of integrating ICT in higher learning institutions in Libya.

To improve the teaching and learning processes, meet the changes in the education market, and satisfy the needs of learners and the community, higher education institutions in Libya have no option but to move with the times and adopt e-learning. Successful initiatives and experiences in neighboring countries can serve as a powerful example for Libyan institutions that may follow their strategies to fulfill the potential of ICT for teaching and learning and to achieve rapid technological development. The integration of e-learning in the education system is likely to gather speed thanks to recent decisions and commitment of the Libyan government. Access to ICT facilities is likely to be improved in the very near future in all Libyan institutions thanks to major infrastructure projects that are currently in progress. However, there is a need for provision of appropriate training at different levels, the development of expertise in e-learning use, and research to gather data and inform future developments; these are important factors that require substantial attention and great effort from the Libyan government to ensure the development of adequate awareness, attitude, and motivation towards e-learning as well as suitable responses.

\section{References}

Abdel-wahab, A. (2008). Modeling students' intention to adopt e-learning a case from Egypt. Turkish Online Journal of Distance Education, 9(1), 157-168.

Ali, A. (2003). Instructional design and online instruction: Practices and perception. TechTrends, 47(5), 4245 .

Andersson, A., \& Grönlund, A. (2009). A conceptual framework for E-learning in developing countries: A critical review of research challenges. The Electronic Journal on Information Systems in Developing Countries, 38(2), 1-16.

Austrade. (2009). Education to Libya. Australian Government Report. Retrieved October 28, 2009, from http://www.austrade.gov.au/Education-to-Libya/default.aspx.

Baylor, A. L., \& Ritchie, D. (2002). What factors facilitate teacher skill, teacher morale, and perceived student learning in technology-using classrooms? Computers \& Education, 39(4), 395-414.

Bozeman, B. (2000). Technology transfer and public policy: A review of research and theory. Research Policy, 2, 627-655. Retrieved November 15, 2009 from

http://calitc.pbworks.com/f/TechTransferStudy.pdf

Chorfi, H., \& Jemini, M. (2002). Innovative e-learning experimentations by use of Waheeb: A Tunisian platform. EDEN Second Research Workshop. Germany.

Clark, N. (2004). Education in Libya. Retrieved October 28, 2009 from http://www.wes.org/ewenr/04July/Practical.htm

Collis, B. A., \& Moonen, J. (2001). Flexible learning in a digital world: Experiences and expectations. London: Kogan Page

Collis, B. A., \& Moonen, J. (2005). An on-going journey: Technology as a learning workbench. Public address, University of Twente, Enschede, The Netherlands. Retrieved October 30, 2009 from http://www.BettyCollisJefMoonen.nl/rb.htm

Elbeltagi, I., McBride, N., \& Hardaker, G. (2005). Evaluating the factors affecting DSS usage by senior managers in local authorities in Egypt. Journal of Global Information Management, 13(2), 42-65.

El-Hawat, A. (2003). African higher education. Libya. 
Towards E-Learning in Higher Education in Libya

The General People's Committee of Education. (2008). The development of education. National report of Libya, Geneva 25- 28 November 2008. Retrieved November 8, 2009 from http://www.ibe.unesco.org/National Reports/ICE 2008/libya NR08.pdf

Gerry, W. (2005). Beyond the horseless carriage: Harnessing the potential of ICT in education and training. Education.au limited. Retrieved October 30, 2009 from http://educationau.edu.au/sites/default/files/horseless_carriages_GW.pdf

Hamdy, A. (2007). ICT in education in Libya. Libya Country Report. Retrieved October 6, 2009 from http://www.infodev.org/en/Document.412.pdf

Hofstede, G. (1980). Culture consequences: International differences in work-related values. London: Sage Publications.

Horton, W. (2000). Designing web-based training. New York: Wiley.

Hu, L., \& Webb, M. (2009). Integrating ICT to higher education in China: From the perspective of activity theory. Education and Information Technologies, 14(2), 143-161.

Iahad, N., Dafoulas, G. A., Milankovic-Atkinson, M., \& Murphy, A. (2004). E-learning in developing countries: suggesting a methodology for enabling computer-aided assessment. Proceedings of the 4th IEEE International Conference on Advance Learning Technologies, 983-987.

Khan, B. (2003). A framework for e-learning. Retrieved September 5, 2009 from http://www.bookstoread.com/framework/

Klauss, R. (2000). Technology transfer in education - Application to developing countries. Journal of Technology Transfer, 25(3), 277-287.

Libya - Education. (2009). Encyclopedia of the Nations. Retrieved October 28, 2009 from http://www.nationsencyclopedia.com/Africa/Libya-EDUCATION.html

Ma, X., Wang, R., \& Liang, J. (2008). The e-learning system model based on affective computing. In Proceedings of the Seventh International Conference on Web-based Learning. College of Computer and Information Engineering, Tianjin Normal University, China.

Mapuva, J. (2009). Confronting challenges to e-learning in higher education institutions. International Journal of Education and Development Using ICT, 5(3).

Rhema, A. (2005). Towards flexible learning: Implementing web-based learning in the Data Analysis Department of the Faculty of Economics and Accounting of the "Aljabal algharbi University" in Gharian in Libya. Unpublished Master thesis, Faculty of Behavioural Science, University of Twente, Enschede, The Netherlands.

Sife, A. S., Lwoga, E. T., \& Sanga, C. (2007). New technologies for teaching and learning: Challenges for higher learning institutions in developing countries. International Journal of Education and Development Using ICT, 3(2), 57-67.

Straub, D. W., Loch, K. D., \& Hill, C. E. (2001). Transfer of information technology to the Arab world: A test of culture influence modeling. Journal of Global Information Management, 9, 6-28.

UNESCO (2005a). Integrating ICTs into the curriculum: Analytical catalogue of key publications. Report. Retrieved September 25, 2009 from http://www.unescobkk.org/fileadmin/user upload/ict/ebooks/Catalogue/Catalogue-preface.pdf

UNESCO (2005b). UNESCO and Libya agree to cooperate in ICT for capacity building project. Report. Retrieved October 28, 2009 from http://unesdoc.unesco.org/images/0014/001458/145852e.pdf

UNESCO (2006). Teachers and educational quality: Monitoring global needs for 2015. Report. Retrieved September 20, 2009 from http://www.uis.unesco.org/TEMPLATE/pdf/Teachers2006/TeachersReport.pdf

Woodrow, J. E. (1992). Locus of control and student teacher computer attitudes. Computers in Education, 14(5), 421-432. 
The World Factbook. (2009). Retrieved October 10, 2009 from:

https://www.cia.gov/cia/publications/factbook/geos/ly.html

\section{Biographies}

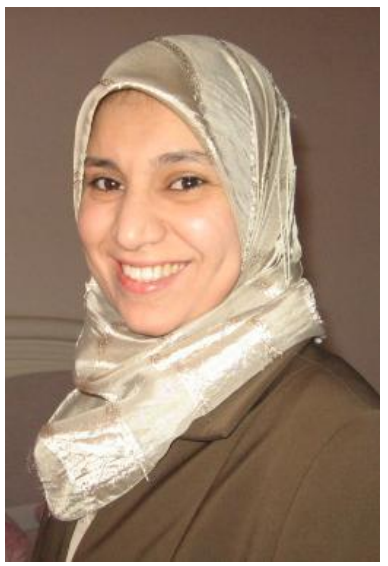

Mrs Amal Rhema is a $\mathrm{PhD}$ candidate in the School of Engineering and Science at Victoria University in Melbourne, Australia where she is currently undertaking a research project entitled "An analysis of experiences and perceptions of technology-based learning in higher education institutions in Libya: informing the advancement of e-learning through case studies".

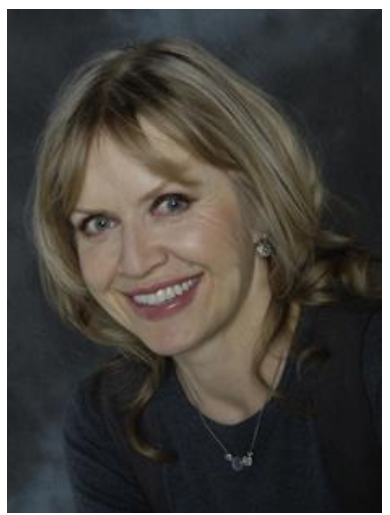

Dr. Iwona Miliszewska is Associate Professor in computer science at Victoria University in Melbourne, Australia. She has led and participated in research projects involving transnational education, effective teaching methods, females in ICT, and technology supported learning and has published in these areas. 